Semin Fetal Neonatal Med. 2009 August ; 14(4): 182-189. doi:10.1016/j.siny.2009.02.003.

\title{
Infection and stillbirth
}

\author{
Elizabeth M. McClure ${ }^{a}$ and Robert L. Goldenberg ${ }^{b, *}$ \\ Robert L. Goldenberg: rgoldenb@drexelmed.edu \\ aDepartment of Epidemiology, UNC Global School of Public Health, Chapel Hill, North Carolina, \\ USA \\ ${ }^{b}$ Department of Obstetrics/Gynecology, Drexel University College of Medicine, 245 N. 15th Street, \\ 17th Floor, Room 17113, Philadelphia, PA 19102, USA
}

\section{Summary}

Infection may cause stillbirth by several mechanisms, including direct infection, placental damage, and severe maternal illness. Various organisms have been associated with stillbirth, including many bacteria, viruses, and protozoa. In developed countries, between $10 \%$ and $25 \%$ of stillbirths may be caused by an infection, whereas in developing countries, which have much higher stillbirth rates, the contribution of infection is much greater. In developed countries, ascending bacterial infection, both before and after membrane rupture, with organisms such as Escherichia coli, group B streptococci, and Ureaplasma urealyticum is usually the most common infectious cause of stillbirth. However, in areas where syphilis is prevalent, up to half of all stillbirths may be caused by this infection alone. Malaria may be an important cause of stillbirth in women infected for the first time in pregnancy. The two most important viral causes of stillbirth are parvovirus and Coxsackie virus, although a number of other viral infections appear to be causal. Toxoplasma gondii, leptospirosis, Listeria monocytogenes, and the organisms that cause leptospirosis, Q fever, and Lyme disease have all been implicated as etiologic for stillbirth. In certain developing countries, the stillbirth rate is high and the infection-related component so great that achieving a substantial reduction in stillbirth should be possible by reducing maternal infections. However, because infection-related stillbirth is uncommon in developed countries, and because those that do occur are caused by a wide variety of organisms, reducing this etiologic component of stillbirth much further will be difficult.

\section{Keywords}

Chorioamnionitis; Infection; Stillbirth

\section{Introduction}

Stillbirth is one of the most common adverse pregnancy outcomes, with an estimated 3.2 million occurring each year worldwide. Rates are as low as 3 per 1000 births in developed countries compared with rates approaching 45 per 1000 in some developing countries. ${ }^{1}$ In recent decades, significant reductions in stillbirths have occurred in many developed countries, primarily due to improved medical care, while rates in developing countries have

\footnotetext{
(C) 2008 Elsevier Ltd. All rights reserved.

*Corresponding author. Tel.: +1 215-762-2014; fax: +1 215-762-2310.
}

Publisher's Disclaimer: This is a PDF file of an unedited manuscript that has been accepted for publication. As a service to our customers we are providing this early version of the manuscript. The manuscript will undergo copyediting, typesetting, and review of the resulting proof before it is published in its final citable form. Please note that during the production process errors may be discovered which could affect the content, and all legal disclaimers that apply to the journal pertain. 
remained high. Stillbirths are frequently classified by presumed etiology. Important noninfectious causes of stillbirth include congenital anomalies, asphyxia, abruptio placentae, and umbilical cord accidents. Maternal and fetal trauma, maternal obesity, advanced maternal age, $\mathrm{Rh}$ disease, and diabetes mellitus are risk factors for stillbirth. More than half of stillbirths are associated with or caused by these conditions. An estimated $10-25 \%$ of stillbirths can be attributed to various maternal or fetal infections, the majority of which are ascending bacterial in origin. ${ }^{2}$ Furthermore, a significant number of stillbirths are multifactorial and thus infection may contribute to many more. We previously reviewed the relationship between infection and stillbirth. ${ }^{3}$ Here, we update that review, including an additional five years of literature.

\section{Definition of stillbirth}

A stillbirth is defined as a birth having no sign of life, such as a heartbeat or spontaneous respiration, after delivery. The lower limits of gestational age used to define a stillbirth have included lower gestational ages ranging from 20 to 28 weeks. Infection is more clearly associated with early (20-28 weeks) compared with late stillbirths (after 28 weeks). ${ }^{4}$ Birth weight appears to have a similar correlation to stillbirth, with an increasing proportion of infection-related stillbirths at lower birth weights. Whereas an accurate gestational age generally is available for births in developed countries, many developing countries rely on a birth weight of $1000 \mathrm{~g}$ to define stillbirth, corresponding to $\sim 28$ weeks. Because of these relationships, studies that only evaluate later fetal deaths occurring after 28 weeks or $>1000$ g may miss the large infectious contribution to early fetal deaths.

\section{Infection and stillbirth}

For various reasons, the relationships between maternal infection and stillbirth are often not very clear. First, knowing exactly why a stillbirth occurred may be difficult. In addition, organisms such as the mycoplasmas/ureaplasmas and certain viruses which are causal are not easily identified. Finding organisms in the placenta or on the fetus does not prove causality. Since infection may initiate a chain of events leading to stillbirth, its role might not be appreciated (e.g. parvovirus causing hydrops). Lastly, positive serologic tests do not prove causality.

Infection may cause stillbirth by a variety of mechanisms including severe maternal illness, direct infection, and placental damage. First, a maternal infection may lead to a systemic illness where the mother is severely ill. Because of the high maternal fever, respiratory distress, or systemic reactions to the illness, the fetus may die without organisms ever being transmitted to the placenta or fetus, e.g. increased rates of stillbirth following influenza pandemics. Second, the placenta may be directly infected, resulting in reduced blood flow to the fetus, e.g. malaria. Third, the fetus may be directly infected through the placenta or membranes, with the organisms damaging a vital organ such as the lung, heart, or brain, e.g. fetal pneumonia associated with Escherichia coli. If an infection occurs very early in gestation, the fetus may not die immediately but have a congenital anomaly with a fetal death occurring later, e.g. rubella. Finally, a maternal infection may precipitate preterm labor with the fetus unable to tolerate labor and born dead. Ureaplasma urealyticum may precipitate early preterm labor by infecting the fetal membranes without causing a fetal infection. A urinary tract infection with $E$. coli is a non-genital tract infection that might precipitate early preterm labor. Thus, stillbirths have been reported in association with virtually all types of infection, including those caused by bacteria, viruses, and many parasites. Nevertheless, of the thousands of infectious agents in the environment, only relatively few have ever been transmitted to the fetus or associated with stillbirth. 


\section{Specific infections related to stillbirth (Table 1)}

\section{Spirochete infections}

Treponema pallidum is the spirochete responsible for syphilis. The rates of infection among women of reproductive age range from $0.02 \%$ in developed countries to as high as $12 \%$ among some African populations. ${ }^{5,6}$ Spirochetes can cross the placenta and infect the fetus at $>14$ weeks' gestation, with risk of fetal infection increasing with gestational age. If the fetus is infected, about $45 \%$ will die in utero, with another $30-40 \%$ born alive but with signs of congenital syphilis. The most common cause of fetal death appears to be placental infection associated with decreasing blood flow to the fetus; direct fetal infection also plays a role. In a review of 33 stillbirths likely caused by syphilis, placental histopathology revealed villous enlargement, acute villitis, erythroblastosis, and necrotizing funisitis indicative of a fetal vasculopathy. ${ }^{7}$ In a multivariate analysis, Potter et al. found that African women with confirmed syphilis were more likely than controls to have had a stillbirth (odds ratio: 2.8 for one stillbirth and 4.3 for $2-5$ previous stillbirths, $P<0.0001)^{8}$ and in a study from Tanzania, $51 \%$ of the stillbirths were attributed to syphilis, with high-titer active syphilis being associated with an 18 -fold increased risk of stillbirth (relative risk: 18.1; $95 \%$ confidence interval: 5.5-59.6) compared with non-infected women. ${ }^{9}$

In areas of southern Africa, where $\geq 10 \%$ of pregnant women may be seropositive, between $25 \%$ and $50 \%$ of all stillbirths are found in seropositive women, with a populationattributable fraction of $25-50 \% .{ }^{10}$ Russia experienced an epidemic of syphilis in the late 1990s with rates increasing from 8 per 100000 in 1991 to 209 per 100000 in 1999. During that period, stillbirth was significantly associated with maternal syphilis $(P<0.01) .{ }^{11} \mathrm{In}$ another example from Africa, Folgosa et al. ${ }^{12}$ found a positive specific serologic test for syphilis in $42 \%$ of stillbirths versus only $12 \%$ of controls. To illustrate the effectiveness of treatment, studies have found that women treated for syphilis had stillbirth risks similar to those of non-infected women. ${ }^{13}$

Another spirochetal infection associated with stillbirth is Lyme disease, a systemic illness caused by the tick-borne spirochete Borrelia burgdorferi. The first case of stillbirth associated with Lyme disease was described in $1987 .{ }^{14}$ In that case, the mother acquired the disease in the first trimester, and at 34 weeks was delivered of a stillborn infant who had $B$. burgdorferi in the placenta and internal fetal organs. In other reports, after first-trimester infection and subsequent fetal death, spirochetes were found in fetal liver, spleen, kidney and brain. Subsequently, small series of stillbirths after maternal Lyme disease have been described, with most deaths occurring in the mid-trimester. However, larger-scale serologic studies have shown that, except in highly endemic areas, few stillbirths are associated with Lyme disease. ${ }^{15}$ In endemic areas in the USA and Norway, the seropositive rate in pregnant women is $\mathcal{2} \%$.

Another spirochetal disease associated with adverse pregnancy outcome, tick-borne relapsing fever, is caused by Borrelia duttonii and transmitted to humans by the tick Ornithodoros moubata, primarily found in sub-Saharan Africa. Studies have reported associations between $B$. duttonii and adverse pregnancy outcomes such as increased perinatal mortality rates. ${ }^{16}$ B. duttonii has also been associated with preterm birth and low birth weight. B. duttonii is predominantly found in sub-Saharan Africa. A study in the Democratic Republic of Congo found that as many as $6.4 \%$ of pregnant women admitted to a maternity ward were diagnosed with relapsing fever. ${ }^{17}$ However, the contribution of this disease to the overall stillbirth rate in endemic areas is unknown. Case reports of relapsing fever during pregnancy have also been reported from the USA. ${ }^{18}$ Finally, leptospirosis, still another spirochetal disease, has been associated with transplacental infection and stillbirth. 
Although not a spirochetal disease, trypanosomiasis, better known as African sleeping sickness transmitted by the tsetse fly, has been associated with stillbirth. The parasites, Trypanosoma brucei, have been demonstrated in placentas of stillborns. How commonly this occurs is unknown. Another trypanosomal illness widespread in South America, Chagas disease, is by T. cruzi and infects the fetus and placenta, causing hydrops and death. ${ }^{19}$ As with African sleeping sickness, the extent to which maternal infection is linked to stillbirth is unknown.

\section{Malaria}

Malaria, one of the world's largest health problems, is caused by one of four intracellular parasites transmitted by various types of mosquitoes. More than $40 \%$ of all births worldwide occur in areas with endemic malaria. ${ }^{20}$ While several studies have examined the prevalence of placental parasitemia in areas of stable endemic malaria in Africa, few have focused on areas with low or unstable transmission. Malaria is generally associated with a wide range of adverse pregnancy outcomes, but especially growth restriction. In endemic areas, malaria approximately doubles the maternal risk of moderate to severe anemia, and increases the risk of preterm birth and fetal growth restriction. The effect of malaria on stillbirth has been difficult to demonstrate. The impact of malaria on pregnancy outcomes varies based on the type of malaria (Plasmodium falciparum has been most commonly implicated in stillbirth; $P$. vivax has only recently been associated with stillbirth), the mother's parity, and her immune status. For example, in primigravid women living within endemic areas, placental malaria occurs in 16-63\% of maternal infections compared with rates of $12-33 \%$ in multigravida women. The clinical presentation of malaria infection during pregnancy varies based on the immunity that women have acquired.

With a maternal malaria infection, pregnancy outcome is directly related to the extent of placental malaria, and in part to the degree of maternal anemia. Histologically, placental malaria is characterized by parasites and leukocytes in the intervillous space and pigment within macrophages. When the parasites infect the placenta, placental insufficiency often results because of lymphocyte and macrophage accumulation, thickening of the trophoblast basement membrane, and increased expression of various proinflammatory cytokines, all of which impede maternal blood flow through the placenta. Placental malaria infection also decreases antibody transfer across the placenta, increasing susceptibility to conditions such as neonatal tetanus. Malarial organisms cross the placenta, and congenital malaria, although not as common as placental infection, certainly occurs. It is difficult to derive an attributable risk of stillbirth associated with malaria in most populations because, when the prevalence of malaria is high, malaria rarely exists in isolation from other risk factors. However, a review of hospital studies, primarily from endemic areas, found that placental malaria was associated with twice the stillbirth risk. ${ }^{21}$ In an Ethiopian study conducted in an area of unstable transmission, Newman et al. ${ }^{22}$ found a seven-fold increased risk of stillbirth compared with no increased risk for women living in endemic areas. This suggests that in populations of pregnant women experiencing a malaria infection for the first time, malaria is likely an important cause of stillbirth. Though a few studies have demonstrated increased risk for stillbirth with malaria in Australia and India, most malaria research has focused on Africa. Further research is needed in geographic areas with low or unstable malarial transmission, such as Asia and Latin America, to better understand the global impact of malaria on stillbirth.

\section{Toxoplasmosis}

Toxoplasmosis gondii is passed to humans through contact with animal feces or from undercooked meat. Past maternal infection, indicated by antibodies, generally protects the pregnant woman from fetal infection. Toxoplasmosis seropositivity in the USA is $\sim 15 \%$, 
but may be much higher in other geographic areas, e.g. one study found that the prevalence of toxoplasmosis antibodies was $>80 \%$ among pregnant Nigerian women. ${ }^{23,24}$

If the mother is infected during pregnancy, toxoplasmosis may be transmitted to the fetus via the placenta. The later the primary maternal infection, the more likely the infection will be transmitted to the fetus. Disseminated toxoplasmosis may cause fetal death. In a case-control study from Jordan, $T$. gondii was significantly more prevalent in women with adverse pregnancy outcomes compared with controls ( $54 \%$ vs $12 \%, P<0.02),{ }^{25}$ while a study from Zimbabwe found that serologic tests for toxoplasmosis were four-fold more common in stillbirths than controls. ${ }^{26}$ Whether toxoplasmosis was the etiologic factor is unknown.

\section{Q fever}

Q fever is a rickettsial infection caused by Coxiella burnetti. In humans this infection is generally acquired by inhalation of infected aerosols during contact with meat products, although transmission has occurred by tick bite and ingestion of infected milk. In nonpregnant adults, $C$. burnetti causes pneumonia, meningoencephalitis, hepatitis, and endocarditis. Infections may be acute or persistent, the latter being mostly asymptomatic, except during pregnancy when the organisms may infect the placenta, leading to abortion, stillbirth, and preterm birth. In a review of cases of acute $\mathrm{Q}$ fever during pregnancy, abnormal pregnancy outcomes were found in all cases of acute maternal infection, with fetal death occurring in two-thirds. ${ }^{27}$ Organisms were generally isolated both from placental and fetal tissues. Most of the stillbirths occurred in the second and early third trimester. The overall contributions of $\mathrm{Q}$ fever to stillbirths, and the actual geographic distribution of $\mathrm{Q}$ fever-associated stillbirths, is unknown. Rocky Mountain spotted fever, another rickettsial disease with widespread distribution in the USA, has not been associated with intrauterine infection or stillbirth.

\section{Viral diseases}

Although it is apparent that viruses cause stillbirths, the overall nature of this relationship is unknown. Many viruses are difficult to culture, a positive viral serologic result does not prove causation, and DNA or RNA viral identification, only recently widely available, is technically difficult. That said, the clearest relationship between any virus and stillbirth is with parvovirus.

Parvovirus (B19) causes a common childhood exanthem - erythema infectiosum - or fifth disease and aplastic anemia in children with sickle cell disease. It was first associated with fetal death in $1984 .{ }^{28}$ Subsequently, investigators have shown that parvovirus crosses the placenta and preferentially attacks erythropoietic tissue, causes fetal anemia, non-immune hydrops, and fetal death. ${ }^{29-31}$ The virus also attacks cardiac tissue and may cause stillbirth by this mechanism. Most stillbirths occur in the second trimester and are associated with hydrops, although parvovirus may also be an important cause of non-hydropic thirdtrimester fetal deaths.

Previous infection elicits an antibody response protective against subsequent maternal and fetal infection. About half of all pregnant women in the USA have had a previous infection, have circulating antibodies, and are immune. Of those not immune, with exposure $\sim 25 \%$ will become infected, and of these $\sim 30 \%$ will pass the virus to their fetus. Of the infected fetuses, only $\sim 10 \%$ will have hydrops; most of these will not die. Therefore, even with maternal infection, the risk of stillbirth is quite low. On the other hand, in a series reported from Sweden, where polymerase chain reaction for viral DNA was used to define fetal parvovirus infection, $15 \%$ of all stillbirths were attributed to parvovirus ${ }^{30}$ with similar results also reported from Germany. ${ }^{31}$ 
Therefore, the proportion of all stillbirths that may be attributable to parvovirus is unclear. Nevertheless, the primary mechanism leading to stillbirth involves the predilection of the virus for bone marrow, resulting in fetal anemia and hydrops. The infections that result in stillbirth are generally acquired before 20 weeks, and death usually occurs in the midtrimester. Overall, in the USA it appears that $<1 \%$ of all stillbirths result from parvovirus infection.

Viral hepatitis is caused by infection with one of the several hepatotropic viruses. Of these viruses, hepatitis E virus (HEV) infection has been associated with adverse outcomes during pregnancy, including maternal death, preterm birth, and stillbirth. HEV generally causes large-scale epidemics, usually through contaminated drinking water. Although the infection is not usually severe in men or non-pregnant women, among pregnant women HEV often results in fulminant hepatic failure and death in up to $20 \%$ of cases. In a recent Indian study, women with HEV infection were twice as likely to have a stillbirth. ${ }^{32}$

Maternal infection with each of the common viral childhood illnesses (chickenpox, rubella, measles, and mumps) has been implicated in causing stillbirths. For example, prior to vaccine development, chickenpox occasionally bypassed some children, who therefore did not develop immunity. They later had chickenpox as an adult during pregnancy. In North America, $\sim 0.5 \%$ of varicella cases occurred during childbearing years. If infected during pregnancy, the woman could be at risk for losing her own life as well as that of her fetus due to the associated maternal pneumonia. The varicella virus also occasionally traversed the placenta and attacked the fetus directly, occasionally damaging a vital organ, killing the fetus. Even before the advent of immunization, these stillbirths occurred only sporadically. Because of widespread immunization, the incidence of chickenpox in pregnancy is decreasing, and the associated stillbirths should decrease as well.

Rubella virus, the etiologic agent for German measles, was first associated with congenital cataracts in $1941 .{ }^{33}$ Subsequently, a wide variety of anomalies have been documented. Some of these may result in stillbirths later in pregnancy. Transmission of the virus to the fetus mostly occurs with maternal disease during the first trimester; the risk of fetal damage decreases as gestational age increases. Rubella also infects the placenta, enhancing the risk of stillbirth, and can do so without fetal spread. With the widespread adoption of the rubella vaccine, congenital rubella infection has become extremely rare in developed countries and plays virtually no role in stillbirths. Although the World Health Organization estimates that half of its member countries have the vaccine, outbreaks are routinely reported from many areas. ${ }^{34}$ Rubella's contribution to stillbirths is unknown. Maternal infection with both mumps and rubeola, or regular measles, have been implicated, although rarely, as a cause of stillbirth, and both viruses have been isolated from fetal tissues. Because of routine vaccination, developed countries have not recently reported stillbirth in association with these viruses. However, in a report from Guinea-Bissau, stillbirth rates increased four- to nine-fold if the mother had been infected with measles during pregnancy. ${ }^{35}$

The enterovirus family includes enterovirus, echovirus, Coxsackie virus, and polio. Each can cross the placenta and cause fetal death. For example, a case report described a woman with Coxsackie virus A9 meningitis at 33 weeks' gestation. ${ }^{36}$ She was delivered of a stillborn infant at 35 weeks whose placenta showed perivillous fibrin deposition and villous necrosis with inflammatory cell infiltration. Coxsackie virus A9 was cultured from the placenta. Furthermore, in a Swedish study, among 21 women with stillbirth, 52\% were Coxsackie B virus positive; among controls, only $22 \%$ were positive. ${ }^{37}$ Echovirus and enteroviruses have also been cultured from stillborns at autopsy where the cause of death appeared to be a fetal viral infection; however, maternal illness and dehydration may have also been factors. ${ }^{38,39}$ Before polio was eradicated from the USA, occasional stillbirths were thought to occur 
because of maternal viral infection, primarily as a result of severe maternal illness and respiratory failure.

Cytomegalovirus (CMV) is the most common congenital viral infection. In the USA, 1-3\% of pregnant women acquire primary CMV during pregnancy. The highest rate of transmission to the fetus, and the most severe consequences, occur with primary infection, probably due to lack of transferred immunity. In many women, the CMV infection is chronic. However, despite the presence of maternal antibodies, the fetus is at some risk. CMV affects $0.2-4.0 \%$ of newborn infants in the USA, and $\sim 11 \%$ of these, or 1:1000 births, are severely affected with pneumonitis and multiple organ failure. Placental involvement is well-documented. Griffiths and Baboonian ${ }^{40}$ in a prospective study of $>10000$ women found increases in fetal loss associated with early CMV infections. Whether CMV actually causes stillbirth and, if so, the mechanism by which it does, is not clear.

Herpes simplex viruses rarely, if ever, cause stillbirth, likely because the virus rarely causes an intrauterine infection; neonatal infections are acquired during fetal passage through an infected birth canal. Although not seen clinically for more than a quarter century, Bernirschke and Robb $^{41}$ note that, before its elimination, maternal smallpox infection frequently caused fatal damage to fetuses, who at the time of autopsy, had extensive necrotic lesions and destructive placental lesions.

Ljungan virus, a recently described Picornavirus of bank voles, was originally isolated in the Ljungan Valley in Sweden. Since then, it has been reported in Denmark and the USA. A recent study of pregnant women found the Ljungan virus in $40 \%$ of stillborns but not in any of the tissue from normal pregnancies. ${ }^{42}$ The lymphocytic choriomeningitis virus has also been implicated as a cause of stillbirth.

Finally, the human immunodeficiency virus (HIV) may cross the placenta and infect the fetus before delivery. Although most studies show no relationship between maternal HIV infection and stillbirth, in one study, HIV-positive women were significantly more likely to have a stillborn infant. ${ }^{43}$ In another study in Zambia, Chi et al. found that among women who were HIV seropositive, decreasing CD4 cell counts were inversely related to stillbirth $(P=0.000)$, suggesting that worsening maternal HIV disease may be associated with stillbirth. The authors speculated that HIV-related immunosuppression might be a factor in adverse pregnancy outcomes among these women. ${ }^{13}$

Studies also have examined the role of HIV co-infection on pregnancy outcome. In one study from western Kenya, women with both HIV and malaria had more adverse pregnancy outcomes than those with either infection alone. Stillbirths were more likely among women with malarial infection, irrespective of HIV status. ${ }^{44}$ Although the role of co-infections on pregnancy outcomes is of interest, especially as HIV becomes a chronic disease, currently it does not appear likely that HIV is causal for stillbirths, other than in those cases where the mother has a severe systemic illness resulting from the HIV.

\section{Bacterial infections}

More than 130 bacterial species are involved in intrauterine infection. These may be divided into bacterial infections which reach the fetal compartment by ascending from the vagina through the cervix or hematogenously through the placenta.

\section{Ascending bacterial infections}

The organisms that ascend from the vagina and infect the uterus and the mechanism by which they cause fetal death have generally been similar over time and across geographic areas. However, the proportion of pregnancies affected by intrauterine bacterial infection is 
likely to be much higher in developing compared with developed countries. The organisms likely ascend from the vagina into the uterus during early pregnancy, but some reside in the uterus before pregnancy. They enter the amniotic fluid either through intact choriodecidual membranes or after the membranes rupture and ultimately infect the fetus. The most common pathway of attack is by way of the fetal lung, associated with fetal breathing of contaminated amniotic fluid. This explains why the most common autopsy finding for many bacterial infection-related stillbirths is pneumonitis.

Intrauterine bacterial infection has also been related to fetal death. The organisms that most frequently infect the fetus are $U$. urealyticum and Mycoplasma hominis, but a large variety of other bacteria including Bacteroides spp., Gardnerella spp., Mobiluncus spp., various enterococci, can cause this infection. For the most part, the organisms have low virulence and may reside in the uterus for months before precipitating preterm labor. Even with the onset of labor, most women do not have classic signs of infection such as fever, chills, or an elevated white count. Instead, the symptoms of this infection seem to be contractions and eventually ruptured membranes. Occasionally, more virulent organisms follow this same pathway and infect the uterine cavity before rupture of membranes. Organisms such as group B streptococci and E. coli have crossed intact fetal membranes and caused amniotic fluid infection. When infection with these organisms occurs, the inflammatory response appears to occur much more rapidly and is more severe, with labor ensuing within hours.

Whether the amniotic fluid infection occurs in the presence of intact membranes or follows membrane rupture, the organisms may be aspirated, enter the fetal lung, and cause severe infection. Whether the fetus is stillborn with congenital pneumonitis or is born alive with pneumonia may depend on the length of time between infection and delivery. Romero et al. ${ }^{45}$ note that a preterm fetal infection generally elicits a fetal inflammatory response and ultimately initiates preterm labor. They suggest that if the fetus cannot initiate an adequate inflammatory response leading to labor or membrane rupture the outcome will likely be a stillbirth.

Amniotic fluid infection has been described in many geographic locations. In most areas, it is a common cause of preterm birth and stillbirth. It is also clear that the frequency of this infection varies by gestational age. Births before 28 weeks are strongly associated with amniotic fluid infection, whereas late preterm births and births at term are much less likely to have this infection. The evidence that amniotic fluid infection is causal for stillbirth comes from several different types of studies. The first compares placental histologic features in stillbirths with placentas from various control groups. In almost every study, the frequency of histologic chorioamnionitis in the stillbirth group is several times greater than in a control group. Furthermore, the more stringent the required histologic evidence for infection, the more likely this finding will be present in the stillbirth group compared with the control group. Therefore, the presence of funisitis or chorionic plate inflammation is often far greater in stillbirths than in appropriate controls. More impressive is the finding of organisms in internal organs at autopsy. For example, a number of autopsy studies cultured organisms such as group B streptococcus, E. coli, and Klebsiella and enterococci from fetal heart blood, liver, lung, and brain. ${ }^{46-48}$ These findings are consistent in studies from Sweden, Lithuania, the USA, and sites in Africa. From Lithuania, for example, fetal bacteremia was found in $36 \%$ of stillbirths but not in controls; half the cases were caused by E. coli. The placentas frequently showed histologic chorioamnionitis and vasculitis. ${ }^{47}$ In studies from Mozambique and Zimbabwe, Bergstrom et al. carefully studied this phenomenon. ${ }^{48-50}$ They found E. coli in $25 \%$ of heart bloods from stillborns and consistently found organisms in internal organs at autopsy, with the fetal lung most commonly infected. In an Ethiopian study, Tafari et al. ${ }^{51}$ noted that, although E. coli and other bacteria were the organisms most often responsible for fetal death, in 23 of 290 (8\%) 
perinatal deaths (mostly late stillbirths), the only organisms identified as responsible for congenital pneumonia and fetal death were mycoplasmas. These infections apparently occurred through intact membranes. Perhaps the most elegant studies were done by Naeye et al. ${ }^{52}$ who studied stillbirths in Ethiopia but also compared their findings to the US Collaborative Perinatal Study. They noted that the mechanism of infection (i.e. ascending from the vagina to the intrauterine cavity) appeared similar in both geographic locations, but that the frequency of stillbirth associated with infection was several times greater in Ethiopia than in the USA. They observed that the rates of infection in early pregnancy were similar in the USA and in Africa. However, although the rate of infection-related stillbirth declined as the gestational age increased in the USA, it persisted at high rates throughout pregnancy in Ethiopia. They speculated that the difference had to do both with the burden of exposure to infectious organisms, which appears to be much greater in Africa, as well as a decreased immune response, believed to be related to the malnutrition so prevalent in African populations. On the basis of histologic observations from Ethiopia, Naeye et al. concluded that $\sim 15 \%$ of all Ethiopian pregnancies were associated with an amniotic fluid infection. In developed countries, the amniotic fluid infection rate appears lower than in developing countries but still plays an important role in stillbirth. For example, in a review of all the stillbirths in Stockholm, Sweden in 1998 and 1999, infections were estimated to have caused $24 \%$ of all stillbirths. ${ }^{53}$ The authors note that $E$. coli, group B streptococci, and enterococci were the major organisms found in internal organs at autopsy. Bergstrom ${ }^{54}$ noted that in the USA Collaborative Perinatal Study, amniotic fluid infection was the most important cause of perinatal deaths.

Of all the bacterial infections associated with stillbirth, special emphasis should be given to group B streptococcal infection. In the middle decades of the 20th century, many reports from developed countries associated stillbirth with an intrauterine infection with this organism. Many of these infections occurred in the presence of intact membranes, but the most common scenario described an intrauterine infection after spontaneous membrane rupture. In one study, 11 of 113 (9.3\%) consecutive stillborn infants had group B streptococci cultured from internal tissues at autopsy. ${ }^{55}$ In another, at autopsy, $45 \%$ of midtrimester stillbirths were associated with a group B streptococcal infection. ${ }^{56}$ Stillbirths associated with group B streptococcal infection virtually always had congenital pneumonia. Overbach et al.$^{57}$ noted that, compared with other intrauterine infections, fetal infection with group B streptococci might not involve inflammation of the fetal membranes. They suggested that, when the organisms enter the uterus after membrane rupture, rapid bacterial replication occurs in the amniotic fluid and fetus with little infection in the membranes themselves. Christensen et al. ${ }^{58}$ noted that fetal mortality associated with group B streptococcal infection often occurred so rapidly that there was minimal fetal inflammatory response. Although stillbirths associated with group B streptococci appear to have decreased substantially in the USA in recent years (but it still occurs ${ }^{59}$ ), in Sweden, group B streptococcus is the most common bacterial infection associated with stillbirth. ${ }^{60} \mathrm{In}$ developing countries, group B streptococcus has consistently been found to be less prevalent. ${ }^{61}$ In those countries, it is not as important a cause of stillbirths as E. coli and other Gram-negative bacteria.

Two other organisms should be mentioned, Chlamydia trachomatis and Neisseria gonorrhoeae. C. trachomatis is the most common sexually transmitted bacterial pathogen. Although both organisms have been found in internal organs at the time of stillbirth autopsy, neither appears to be a significant factor in stillbirths. ${ }^{3}$ In other case reports, a related organism, Chlamydia abortus, which causes fetal wastage among infected sheep, has been attributed to stillbirth among farm women. The reason for their minimal involvement in stillbirths may be related to the fact that, as opposed to many other bacteria such as $U$. urealyticum, during pregnancy neither bacterium appears routinely to ascend into the uterus. 
Galask et al. ${ }^{62}$ suggest that, at least for $N$. gonorrheae, the reason for failure to ascend into the uterus during pregnancy is due to its inability to attach to the fetal membranes.

\section{Hematogenously acquired bacterial infections}

Bacteria also reach the fetus through the placenta. When that occurs, the placenta will often have evidence of infection, including a white blood cell response, microabscesses, and infarction. The organisms generally enter the fetus through the umbilical vein; for that reason the liver is the organ most often infected. Listeria monocytogenes is an excellent example of a hematogenously transmitted organism that causes fetal death. Infection is acquired by the mother, usually by eating contaminated food. The organisms are transmitted hematogenously to the placenta. In some cases, the organisms are transmitted to the fetus and the fetal deaths are attributed both to placental dysfunction, often associated with growth restriction, and direct infection of the fetus. On rare occasions, bacterial infection of the fetal liver and stillbirth has been reported in association with maternal tularemia, anthrax, typhoid fever, and brucellosis, the plant bacterium Agrobacterium radiobacter, Haemophilus influenzae, Pseudomonas pyocyanea, clostridial infections and Candida albicans.

Referring to the potential mechanisms of death associated with infection-caused stillbirth, we have so far considered predominantly those amniotic fluid infections in which the organisms attack the fetus directly causing pneumonitis and sepsis. However, it is also apparent that many of the earliest stillbirths occur without the organisms actually reaching the fetus. Instead, bacterial infections may cause stillbirth by precipitating preterm labor, and perhaps intrauterine bleeding, with the fetus dying in relationship to one of those conditions. Placental damage, including thrombosis, resulting from these infections also may cause decreased oxygenation, resulting in stillbirth by that mechanism.

Overall, by a number of mechanisms, it appears that in developed countries, between 1 and 2 pregnancies in 1000 end in a stillbirth caused by a bacterial infection. With overall stillbirth rates from 20 weeks through term ranging from 6 to 8 per 1000 births in many developed countries, this suggests that between 1 and 2 of the 6-8 per 1000 stillbirths occur in relation to a bacterial intrauterine infection. In developing countries, where the stillbirth rates may be 10 times those in developed countries, it appears that a much larger proportion of stillbirths is related to bacterial intrauterine infection. The proportion attributed to infection depends in part upon the classification system used to establish causality.

\section{Classifying infection as a cause of stillbirths}

More than 30 classification systems have been developed since the 1950s to assign cause of stillbirth. Generally, each system uses a set of information available about the maternal and/ or fetal conditions and then applies criteria to assign a cause of stillbirth. Among the systems available are the Wigglesworth, Aberdeen, and the Relevant Conditions at Death (ReCoDe). The Wigglesworth system uses a pathophysiological approach and is combined with stratification by birthweight classes, intending to create functional groups. The Aberdeen classification, originally developed by Baird in 1954, and adapted for use in developing countries, ascribes the death to predisposing obstetric events or to the underlying cause. ${ }^{63,64}$ The more recently developed ReCoDe system attempts to identify the relevant conditions at the time of death in utero. ${ }^{65}$ From all available evidence, the particular classification system used influences the percentage of cases in which infection is attributed to stillbirth. Also, it is clear that the quantity and quality of data are crucial to determining whether infection was involved in any particular stillbirth. For example, using most classification systems the cause of more than half the stillbirths remains unknown. We suspect that with more vigorous search for infection, this percentage will fall. The best proof of an infectious etiology is a 
carefully performed autopsy and placental examination with appropriate serologic studies, cultures, and DNA specimens taken for the organisms discussed in this report. However, even if an autopsy is not performed, a histologic study of the placenta, membranes, and umbilical cord, with appropriate bacterial, viral, and protozoan serologic studies, culture, and DNA isolation techniques, will often provide evidence for an infectious etiology.

\section{Prevention of infection-related stillbirth}

Because of the very low incidence of infection-related stillbirths in many developed countries, reducing this component still further may be quite difficult. Even development of vaccines for some of the viral causes of stillbirth (parvovirus, Coxsackie A and B) would likely have only a small impact on the stillbirth rates. Stillbirths associated with toxoplasmosis occur so rarely that educational attention to hand washing will not have a discernible impact in most places. Greater attention to preventing Lyme disease might reduce the few stillbirths associated with this condition. However, the largest potential benefit appears to be related to stillbirths associated with bacterial intra-amniotic infections. In a number of geographic areas, health care providers do not screen for or treat group B streptococcus, and certainly stillbirths caused by this organism occur both before and after membrane rupture. The high percentage of group B streptococcal-related stillbirths in Sweden, a country that does not routinely screen for this organism, suggests room for improvement. On the other hand, although not a consistent observation, antibiotic prophylaxis against group B streptococci may be associated with an increase in fetal Gramnegative and especially E. coli infections. Therefore, it is unknown whether group B streptococcal screening and treatment programs will actually reduce the number of stillbirths associated with this organism or even whether they reduce the overall infection-related stillbirth rate because they may substitute stillbirths associated with one organism for another. Also, although large numbers of stillbirths have not been associated with ascending bacterial infection after premature rupture of the membranes (PROM), the current recommended antibiotic treatment strategies certainly reduce chorioamnionitis and likely reduce stillbirth as well. Whether treatment of bacterial vaginosis will reduce stillbirths is unknown. However, continued attention to screening and treatment of the sexually transmitted infections, including syphilis, chlamydia, and gonorrhea, should minimize stillbirths associated with these infections.

In many developing countries, the infectious disease burden during pregnancy is extremely high, and the stillbirth rate is high as a result of these infections. In some countries, effective programs to screen for and treat syphilis and the other sexually transmitted infections should have a major impact on the number of stillbirths. A trial in Tanzania found a single dose treatment for syphilis to be effective in reducing the stillbirth risk of infected women to that of non-infected women. ${ }^{66}$ Reducing maternal malaria infection in newly endemic areas or in newly infected pregnant women in endemic areas should also reduce stillbirths and effective strategies have been evaluated specifically for treatment during pregnancy. In developing countries, it is also likely that reduction in amniotic fluid infections, if achievable, will have a substantial impact on stillbirth rates. Potential strategies (which should be tested in appropriate randomized trials) for use in these countries include nutritional supplementation with vitamin/mineral preparations, calories, or both, and a reduction in genital tract bacterial exposure by use of antibiotics or vaginal/newborn Chlorhexidine washes, and effective management of both preterm and term PROM. Achieving high antiviral vaccination rates (rubella, varicella, polio) should reduce these related stillbirths. Most important is monitoring the infection-related stillbirths in developing countries to learn the number of stillbirths associated with specific infections and initiate effective strategies to reduce their occurrence. 


\section{Conclusion}

In developed countries, the most common intrauterine infection causing stillbirths appears to be bacteria ascending from the vagina. In developing countries, most infection-related stillbirths appear to be caused by T. pallidum, malaria, and intrauterine infection with common vaginal organisms. A research agenda (panel) addressing the infectious contributions to stillbirth, including intra-amniotic infection, and especially in developing countries, the contribution of vector-borne and viral infections, and effective prevention of syphilis and malaria, is needed to reduce stillbirth worldwide.

\section{References}

1. Stanton C, Lawn JE, Rahman H, Wilczynska-Ketende K, Hill K. Stillbirth rates: delivering estimates in 190 countries. Lancet. 2006; 367(9521):1487-94. [PubMed: 16679161]

2. Rawlinson WD, Hall B, Jones CA, et al. Viruses and other infections in stillbirth: what is the evidence and what should we be doing? Pathology. 2008; 40:149-60. [PubMed: 18203037]

3. Gibbs RS. The origins of stillbirth: infectious diseases. Semin Perinatol. 2002; 26:75-8. [PubMed: 11876570]

4. Goldenberg RL, Hauth JC, Andrews WW. Intrauterine infection and preterm delivery. N Engl J Med. 2000; 342:1500-7. [PubMed: 10816189]

5. Lumbiganon P, Piaggio G, Villar J, et al. The epidemiology of syphilis in pregnancy. Int J STD AIDS. 2002; 13:486-94. [PubMed: 12171669]

6. Anonymous. Congenital syphilis-United States, 2000. Morb Mortal Wkly Rep. 2001; 50:573-7.

7. Sheffield JS, Sanchez PJ, Wendel GD, et al. Placental histopathology of congenital syphilis. Obstet Gynecol. 2002; 100:126-33. [PubMed: 12100814]

8. Potter D, Goldenberg RL, Read JS, et al. Correlates of syphilis seroreactivity among pregnant women: The HIVNET 024 trial in Malawi, Tanzania and Zambia. Sexually Transm Dis. 2006; 33:604-9.

9. Watson-Jones D, Changalucha J, Gumadoka B, et al. Syphilis in pregnancy in Tanzania. I. Impact of maternal syphilis on outcome of pregnancy. J Infect Dis. 2002; 186:940-7. [PubMed: 12232834]

10. Di Mario S, Say L, Lincetto O. Risk factors for stillbirth in developing countries: a systematic review of the literature. Sexually Transm Dis. 2007; 34:S11-S21.

11. Salakhov E, Tikhonova L, Southwick K, Shakarishvili A, Ryan C, Hillis C. Congenital syphilis in Russia: the value of counting epidemiologic cases and clinical cases. Sexually Transm Dis. 2004; 31:127-32.

12. Folgosa E, Osman NB, Gonzalez C, Hagerstrand I, Bergstrom S, Ljungh A. Syphilis seroprevalence among pregnant women and its role as a risk factor for stillbirth in Maputo, Mozambique. Genitourin Med. 1996; 72:339-42. [PubMed: 8976849]

13. Chi BH, Wang L, Read JS, et al. Predictors of stillbirth in sub-saharan Africa. Obstet Gynecol. 2007; 110:989-97. [PubMed: 17978109]

14. MacDonald A, Benach J, Burgdorfer W. Stillbirth following maternal Lyme disease. NY State J Med. 1987; 87:615-16.

15. Strobino BA, Williams CL, Abid S, Chalson R, Spierling P. Lyme disease and pregnancy outcome: a prospective study of two thousand prenatal patients. Am J Obstet Gynecol. 1993; 169:367-74. [PubMed: 8362948]

16. McConnell J. Tick-borne relapsing fever under-reported. Lancet Infect Dis. 2003; 3:604. [PubMed: 14558501]

17. Dupont HT, La Scola B, Williams R, Raoult D. A focus of tick-borne relapsing fever in southern Zaire. Clin Infect Dis. 1997; 25:139-44. [PubMed: 9243047]

18. Guggenheim JN, Havercamp AD. Tick-borne relapsing fever during pregnancy: a case report. J Reprod Med. 2005; 50:727-9. [PubMed: 16363764]

19. Buekens P, Almendares O, Carlier Y, et al. Mother-to-child transmission of Chagas' disease in North America: why don't we do more? Matern Child Health J. 200710.1007/s10995-007-0246-8 
20. Desai M, Oter Kuile F, Nosten F, et al. Epidemiology and burden of malaria in pregnancy. Lancet Infect Dis. 2007; 7:93-104. [PubMed: 17251080]

21. Van Greertruyden JP, Thomas F, Erhart A, D'Alessandro U. The contribution of malaria in pregnancy to perinatal mortality. Am J Trop Med Hyg. 2004; 71(Suppl):35-40. [PubMed: 15331817]

22. Newman RD, Hailemariam A, Jimma D, et al. Burden of malaria during pregnancy in areas of stable and unstable transmission in Ethiopia during a non-epidemic year. J Infect Dis. 2003; 187:1765-72. [PubMed: 12751034]

23. Jones JL, Lopez A, Wilson M, Schulkin J, Gibbs R. Congenital toxoplasmosis: a review. Obstet Gynecol Surv. 2001; 56:296-305. [PubMed: 11333376]

24. Onadeko MO, Joynson DH, Payne RA, Francis J. The prevalence of toxoplasma antibodies in pregnant Nigerian women and the occurrence of stillbirth and congenital malformation. Afr J Med Med Sci. 1996; 25:331-4. [PubMed: 9532302]

25. Nimri L, Pelloux H, Elkhatib L. Detection of Toxoplasma gondii DNA and specific antibodies in high-risk pregnant women. Am J Trop Med Hyg. 2004; 71:831-5. [PubMed: 15642979]

26. Osman NB, Folgosa E, Gonzales C, Bergstrom S. Genital infections in the aetiology of late fetal death: an incident case-referent study. J Trop Pediatr. 1995; 41:258-66. [PubMed: 8531255]

27. Raoult D, Fenollar F, Stein A. Q fever during pregnancy. Arch Intern Med. 2002; 162:701-4. [PubMed: 11911725]

28. Brown T, Anand A, Ritchie LD, Clewley JP, Reid TM. Intrauterine parvovirus infection associated with hydrops fetalis. Lancet. 1984; 2:1033-4. [PubMed: 6149411]

29. Skjoldebrand-Sparre L, Tolfvenstam T, Papadogiannakis N, Wahren B, Broliden K, Nyman M. Parvovirus B19 infection: association with third-trimester intrauterine fetal death. Br J Obstet Gynaecol. 2000; 107:476-80.

30. Tolfvenstam T, Papadogiannakis N, Norbeck O, Petersson K, Broliden K. Frequency of human parvovirus B19 infection in intrauterine fetal death. Lancet. 2001; 357:1494-7. [PubMed: 11377602]

31. Enders M, Weidner A, Zoellner I, Searle K, Enders G. Fetal morbidity and mortality after acute human parvovirus B19 infection in pregnancy: a prospective evaluation of 1018 cases. Prenat Diagn. 2004; 24

32. Aggarwal R. Hepatitis E, pregnancy. Ind J Gastroenterol. 2007; 26:3-5.

33. Gregg NM. Congenital cataract following German measles in the mother. Trans Ophthalmol Soc Aust. 1941; 3:35-46.

34. Dayan GH, Zimmerman L, Shteinke L, et al. Investigation of a rubella outbreak in Kyrgyzstan in 2001: implications for an integrated approach to measles elimination and prevention of congenital rubella sundrome. J Infect Dis. 2003; 187:S235-40. [PubMed: 12721919]

35. Aaby P, Bukh J, Lisse IM, Seim E, de Silva MC. Increased perinatal mortality among children of mothers exposed to measles during pregnancy. Lancet. 1988; 1:516-9. [PubMed: 2893927]

36. Batcup G, Holt P, Hambling MH, Gerlis LM, Glass MR. Placental and fetal pathology in Coxsackie virus A9 infection: a case report. Histopathology. 1985; 9:1227-35. [PubMed: 4085986]

37. Frisk G, DIderholm H. Increased frequency of Coxsackie B virus IgM in women with spontaneous abortion. J Infect. 1992; 24:141-5. [PubMed: 1314861]

38. Basso NG, Fonseca ME, Garcia AG, Zuardi JA, Silva MR, Outani H. Enterovirus isolation from fetal and placental tissues. Acta Virol. 1990; 34:49-57. [PubMed: 1975725]

39. Nielsen JL, Berryman GK, Hankins GDV. Intrauterine fetal death and the isolation of echovirus 27 from amniotic fluid. J Infect Dis. 1988; 158:501-2. [PubMed: 3404002]

40. Griffiths PD, Baboonian C, Rutter D, Peckham C. Congenital and maternal cytomegalovirus infections in a London population. Br J Obstet Gynaecol. 1991; 98:135-40. [PubMed: 1848445]

41. Benirschke K, Robb J. Infectious causes of fetal death. Clin Obstet Gynecol. 1987; 30:284-94. [PubMed: 3038445]

42. Nicklasson B, Samsioe A, Papadogiannakis N, et al. Association of Zoonotic Ljungan Virus with intrauterine fetal deaths. Birth Def Res. 2007; 79:488-93. 
43. Brocklehurst $\mathrm{P}$, French R. The association between maternal HIV infection and perinatal outcome: a systematic review of the literature and meta-analysis. Br J Obstet Gynaecol. 1998; 105:836-48. [PubMed: 9746375]

44. Ayisi JG, van Eijk AM, ter Kuile FO, et al. The effect of dual infection with HIV and malaria on pregnancy outcome in western Kenya. AIDS. 2003; 17:585-94. [PubMed: 12598779]

45. Romero R, Gomez R, Ghezzi F, et al. A fetal systemic inflammatory response is followed by the spontaneous onset of preterm parturition. Am J Obstet Gynecol. 1998; 179:186-93. [PubMed: 9704786]

46. Axemo P, Ching C, Machungo F, Osman NB, Bergstrom S. Intrauterine infections and their association with stillbirth and preterm birth in Maputo, Mozambique. Gynecol Obstet Invest. 1993; 35:108-13. [PubMed: 8449441]

47. Maleckiene L, Nadisauskiene R, Stankeviciene I, Cizauskas A, Bergstrom S. A case-referent study on fetal bacteremia and late fetal death of unknown etiology in Lithuania. Acta Obstet Gynecol Scand. 2000; 79:1069-74. [PubMed: 11130090]

48. Tolockiene E, Morsing E, Holst E, et al. Intrauterine infection may be a major cause of stillbirth in Sweden. Acta Obstet Gynecol Scand. 2001; 80:511-8. [PubMed: 11380286]

49. Moyo SR, Tswana SA, Nystrom L, Bergstrom S, Blomberg J, Ljungh A. Intrauterine death and infections during pregnancy. Int J Gynaecol Obstet. 1995; 51:211-8. [PubMed: 8745085]

50. Bergstrom S. Genital infections and reproductive health: infertility and morbidity of mother and child in developing countries. Scand J Infect Dis. 1990; 69:99-105.

51. Tafari N, Ross S, Naeye RL, Judge DM, Marboe C. Mycoplasma T strains and perinatal death. Lancet. 1976; 1:108-9. [PubMed: 54632]

52. Naeye RL, Tafari N, Judge D, Gilmour D, Marboe C. Amniotic fluid infections in an African city. J Pediatr. 1977; 90:965-70. [PubMed: 859070]

53. Petersson K, Bremme K, Bottinga R, et al. Diagnostic evaluation of intrauterine fetal deaths in Stockholm 1998-99. Acta Obstet Gynecol Scand. 2002; 81:284-92. [PubMed: 11952456]

54. Bergstrom S. Genital infections and reproductive health: infertility and morbidity of mother and child in developing countries. Scan J Infect Dis. 1990; 69:99-105.

55. Hood M, Janney A, Damerson G. Beta hemolytic Streptococcus group B associated with problems of the perinatal period. Am J Obstet Gynecol. 1961; 82:809-18. [PubMed: 13908742]

56. Becroft DMO, Farmer K, Mason GH, Morris MC, Steward JH. Perinatal infection by group B Bhaemolytic streptococci. J Perinat Med. 1982; 10:133-46. [PubMed: 7050338]

57. Overbach AM, Daniel SH, Cassady G. The value of umbilical cord histology in the management of potential perinatal infection. J Pediatr. 1970; 76:22-31. [PubMed: 5410157]

58. Christensen KK, Christensen P, Hagerstrand I, Linden V, Nordbring F, Svenningsen N. The clinical significance of group B streptococci. J Perinat Med. 1982; 10:133-46. [PubMed: 7050338]

59. Gibbs RS, Roberts DJ. Case 27-2007: a 30-year-old pregnant woman with intrauterine fetal death. N Engl J Med. 2007; 357:918-25. [PubMed: 17761596]

60. Petersson K, Bremme K, Bottinga R, et al. Diagnostic evaluation of intrauterine fetal deaths in Stockholm 1998-99. Acta Obstet Gynecol Scand. 2002; 81:284-292. [PubMed: 11952456]

61. Folgosa E, Gonzalez C, Osman NB, Hägerstrand I, Bergström S, Ljungh A. A case control study of chorioamniotic infection and histological chorioamnionitis in stillbirth. APMIS. 1997; 105:32936. [PubMed: 9164478]

62. Galask RP, Varner MW, Petzold R, Wilbur SL. Bacterial attachment to the chorioamniotic membranes. Am J Obstet Gynecol. 1984; 148:915-28. [PubMed: 6424476]

63. Wigglesworth J. Classification of perinatal deaths. Soc Prev Med. 1994; 39:11-14.

64. Pattinson RC, De Jong G, Theron GB. Primary causes of total perinatally related wastage at Tygerberg Hospital. S Afr Med J. 1989; 75:50-3. [PubMed: 2643836]

65. Gardosi J, Kady SM, McGeown P, Francis A, Tonks A. Classification of stillbirth by relevant condition at death (ReCoDe): population based cohort study. Br Med J. 2005; 331(7525):1113-7. [PubMed: 16236774] 
66. Watson-Jones D, Weiss HA, Changalucha JM, et al. Adverse birth outcomes in United Republic of Tanzania - impact and prevention of maternal risk factors. Bull WHO. 2007; 85:9-17. [PubMed: 17242753] 
- In all locations, to identify interventions that will reduce stillbirth associated with intra-amniotic infection.

- In developing countries, to determine the contribution of various vector-borne and other tropical diseases to stillbirth.

- In developing countries, to determine the role of viral infections including measles, mumps and chickenpox, in stillbirths.

- In endemic areas, to implement programs that will reduce stillbirth associated with syphilis and malaria. 
Table 1

\section{Maternal infections and stillbirths}

\begin{tabular}{|c|c|c|}
\hline Organism & Maternal disease & Comment \\
\hline \multicolumn{3}{|l|}{ Spirochetes } \\
\hline Treponema pallidum & Syphilis & $\begin{array}{l}\text { Major cause of stillbirth when maternal } \\
\text { prevalence is high }\end{array}$ \\
\hline Borrelia burgdorferi & Lyme disease & $\begin{array}{l}\text { Confirmed relationship but not common cause of } \\
\text { stillbirth }\end{array}$ \\
\hline Borrelia recurrentis & Tick-borne relapsing fever & $\begin{array}{l}\text { Rarely associated, of unknown importance as } \\
\text { cause of stillbirth }\end{array}$ \\
\hline Leptospira interrogans & Leptospirosis & Confirmed as cause of stillbirth but not common \\
\hline \multicolumn{3}{|l|}{ Protozoa } \\
\hline Trypanosoma brucei & Trypanosomiasis & Not certain cause of stillbirth \\
\hline Trypanosoma cruzi & Chagas disease & $\begin{array}{l}\text { Confirmed as cause of stillbirth in South America } \\
\text { but of unknown importance }\end{array}$ \\
\hline $\begin{array}{l}\text { Plasmodium falciparum, Plasmodium } \\
\text { vivax }\end{array}$ & Malaria & $\begin{array}{l}\text { Likely important cause of stillbirth in newly } \\
\text { endemic areas or in newly infected women }\end{array}$ \\
\hline Toxoplasmosis gondii & Toxoplasmosis & Confirmed as cause of stillbirth but not common \\
\hline Coxiella burnetti & Q fever & $\begin{array}{l}\text { Confirmed as cause of stillbirth but of unknown } \\
\text { importance }\end{array}$ \\
\hline \multicolumn{3}{|l|}{ Viruses } \\
\hline Parvovirus (B19) & Erythema infectiosum & $\begin{array}{l}\text { Confirmed as cause of stillbirth, likely most } \\
\text { common viral etiologic agent }\end{array}$ \\
\hline Coxsackie A and B & Various presentations & $\begin{array}{l}\text { Confirmed as causes of stillbirth, may be } \\
\text { important contributor }\end{array}$ \\
\hline Echovirus & Various presentations & $\begin{array}{l}\text { Confirmed as cause of stillbirth but of unknown } \\
\text { importance }\end{array}$ \\
\hline Enterovirus & Various presentations & $\begin{array}{l}\text { Confirmed as cause of stillbirth but of unknown } \\
\text { importance }\end{array}$ \\
\hline Hepatitis E virus & Fulminant hepatic failure & $\begin{array}{l}\text { Possibly cause of risk factor, especially in } \\
\text { geographic areas with epidemic outbreaks }\end{array}$ \\
\hline Polio virus & Polio & $\begin{array}{l}\text { Historically likely cause of stillbirth but since } \\
\text { routine vaccination no longer seen in developed } \\
\text { countries }\end{array}$ \\
\hline Varicella zoster & Chickenpox & Confirmed as cause of stillbirth but not common \\
\hline Rubella & German measles & $\begin{array}{l}\text { Confirmed, but no longer cause of stillbirth in } \\
\text { developed countries }\end{array}$ \\
\hline Mumps & Parotitis & $\begin{array}{l}\text { Possibly cause of stillbirth historically but no } \\
\text { longer cause of stillbirth in developed countries }\end{array}$ \\
\hline Rubella & Measles & Possibly cause of stillbirth historically \\
\hline Cytomegalovirus & Generally asymptomatic in adults & Rarely if ever cause of stillbirth \\
\hline Variola & Smallpox & Historically cause of stillbirth but no longer seen \\
\hline Ljungan virus & $\begin{array}{l}\text { Diabetes, neurological disease, myocarditis } \\
\text { and deaths }\end{array}$ & $\begin{array}{l}\text { Associated with several cases of stillbirth in a } \\
\text { single report }\end{array}$ \\
\hline Lymphocytic choriomeningitis virus & Lymphocytic choriomeningitis & $\begin{array}{l}\text { Not confirmed as cause of stillbirth, of unknown } \\
\text { importance }\end{array}$ \\
\hline Human immunodeficiency virus & Acquired immunodeficiency syndrome & Associated with stillbirth but not likely causative \\
\hline \multicolumn{3}{|l|}{ Bacteria } \\
\hline E. coli & Generally asymptomatic & $\begin{array}{l}\text { Confirmed, probably the most common organism } \\
\text { associated with stillbirth }\end{array}$ \\
\hline
\end{tabular}




\begin{tabular}{lll}
\hline Organism & Maternal disease & Comment \\
\hline Group B streptococcus & Generally asymptomatic & Confirmed as common cause of stillbirth \\
Klebsiella & Generally asymptomatic & Confirmed, common cause of stillbirth \\
Enterococcus & Generally asymptomatic & Confirmed \\
U. urealyticum & Generally asymptomatic & Confirmed \\
Mycoplasma hominus & Generally asymptomatic & Confirmed \\
Bacteroidaceae & Generally asymptomatic & Confirmed \\
Listeria monocytogenes & Listerosis & Confirmed, generally transmitted transplacentally \\
Other bacteria including brucellosis, & & Potentially implicated as causal for stillbirth by \\
Pseudomonas, etc. & & case reports \\
Chlamydia trachomatis & & Suggested as cause of stillbirth by case reports \\
Neiserria gonorrhoeae & Pelvic infection & Suggested as cause of stillbirth by case reports \\
Fungi & Pelvic infection & \\
Candida albicans & & Confirmed as cause of stillbirth by case reports \\
\hline
\end{tabular}

